\title{
The impact of coupled games on the learning experience of learners at-risk: An empirical study
}

Citation for published version (APA):

Schmitz, B., Klemke, R., \& Specht, M. (2014). The impact of coupled games on the learning experience of learners at-risk: An empirical study. Pervasive and Mobile Computing, 14, 57-65.

https://doi.org/10.1016/j.pmcj.2013.09.002

DOI:

10.1016/j.pmcj.2013.09.002

Document status and date:

Published: 01/10/2014

Document Version:

Peer reviewed version

Please check the document version of this publication:

- A submitted manuscript is the version of the article upon submission and before peer-review. There can be important differences between the submitted version and the official published version of record. People interested in the research are advised to contact the author for the final version of the publication, or visit the DOI to the publisher's website.

- The final author version and the galley proof are versions of the publication after peer review.

- The final published version features the final layout of the paper including the volume, issue and page numbers.

Link to publication

\section{General rights}

Copyright and moral rights for the publications made accessible in the public portal are retained by the authors and/or other copyright owners and it is a condition of accessing publications that users recognise and abide by the legal requirements associated with these rights.

- Users may download and print one copy of any publication from the public portal for the purpose of private study or research.

- You may not further distribute the material or use it for any profit-making activity or commercial gain

- You may freely distribute the URL identifying the publication in the public portal.

If the publication is distributed under the terms of Article 25fa of the Dutch Copyright Act, indicated by the "Taverne" license above, please follow below link for the End User Agreement:

https://www.ou.nl/taverne-agreement

Take down policy

If you believe that this document breaches copyright please contact us at:

pure-support@ou.nl

providing details and we will investigate your claim.

Downloaded from https://research.ou.nl/ on date: 26 Apr. 2023 


\title{
The impact of coupled games on the learning experience of learners at-risk: An empirical study
}

\author{
Birgit Schmitz, Roland Klemke, Marcus Specht
}

\begin{abstract}
Offering pervasive game-based learning scenarios to at-risk learners is considered effective and motivating. This experimental study offers a detailed example of an educational setting that couples a mobile game with a PC browser game. It evaluates how this coupling supports engagement and learning for the target group. Nineteen participants aged between 17 and 21 years played and explored the game. The findings through seven-week gaming indicate that coupled games have potential to increase learners' interest in a topic and can support learning activities.
\end{abstract}

Keywords: educational games, pervasive technology, SMS notifications, mobile game design patterns, learning outcomes, at-risk learners

\section{INTRODUCTION}

Todays young adults have grown up using devices like computers, mobile phones, and video consoles for almost any activity. Their habits in using media strongly contrast with traditional schooling methods, which seem little motivating in the light of these devices [1]. While young adults conduct a substantial part of their lives via the mobile phone, schools and universities have long pursued other forms of educational interaction and contact [2]. However, for nearly half a decade now, digital and in particular pervasive game-based learning scenarios have started to gain traction among educational practitioners [3][4][5].

Pervasive learning games provide motivating, low-threshold learning opportunities and enable the creation of situated learning scenarios that enhance encoding and recall [6][7]. As Traxler 
[8] points out, mobile devices provide chances to counteract social exclusion by offering learning opportunities for students "unfamiliar with and lacking confidence in formal learning and its institutions, e.g. the homeless, gypsies, marginal groups, and NEETs (Not in Education, Employment or Training)" (p. 132), providing them chances to develop and improve confidence, autonomy, and engagement [9]. Especially the NEET group comprises individuals who, regardless of their educational level, are disengaged from work and education and are therefore at a higher risk of labor market and social exclusion [10]. They are regularly associated with negative respondence to educational offers, difficulty adjusting to school, unacceptable social behaviour, or literacy and numeracy needs [11]. On the basis of a multitude of cultural, social and/or socioeconomic problems, these learners are at risk of dropping out of school. They have been excluded or truanted due to disaffection or bullying and often face difficult personal circumstances such as caring responsibilities, domestic violence, or learning disabilities [12]. The target group's personal, economic and social backgrounds have thus led to a lack of "the cognitive schemata upon which classroom intruction is ordinarily based" [11, p. 37]. Consequently, "their opportunity of functioning successfully as adults in roles associated with work and family is jeopardized" [13, p. 30]. It is thus one of the main challenges for the educational system to bring these youngsters back into education and training.

From their learning history the target group has concluded that school and education are something difficult to handle. In most of the cases this has led to disengagement from both work and education [10]. Innovative, media-based forms of learning and teaching that include mobile devices and game environments may countervail the "alienating classroom" [11] and are thus regarded as one toehold to face the challenge. The increasing spread and technical capabilities of mobile devices support this development.

With this work we scrutinize how at-risk learners with different abilities and capacities can be effectively and efficiently supported by a mobile learning game. In order to do so, we employ game design patterns for mobile games [14] and more specifically the pattern Coupled Games 
[15]. Patterns have become a recognized approach to better understanding the complex issue of digital game-based learning. Recent studies have thus started to explicitly focus on the effects of individual patterns as a learning intervention [16][17][18][19][20][21]. With this paper, we aim at contributing to this research. In our research we use patterns provided by Davidsson [14], these patterns advance the work of Björk and Holopainen [17]. Davidsson has described game design patterns by a core definition, a general definition, example(s), descriptions of how to use the pattern (by listing related patterns or patterns that can be linked to it), the description of its consequences, relations with regard to instantiation (patterns causing each other's presence) and modulation (patterns influencing each other), as well as references [11]. In the context of our ongoing research we focus on the pattern Coupled Games.

Coupled Games are defined as games that share some amount of player-accessible data. They "always refer to at least two games. A single game cannot be coupled. The coupling occurs when the games in question share some data" $[14, \mathrm{p} .16]$. The shared data can be anything from player specific data, vitual ressources such as gold coins, to the actual world where the game takes place. The game Sonic Adventures (Sega), for example, uses this pattern. Sonic Adventures is a console game. As part of the game, players have to find Chao Eggs, which they can hatch and transfer to a Gameboy Advance. The Chao can then be raised on the mobile device and separately from the console game. The pattern Coupled Games is instantiated by (caused by the use of), e.g., the pattern Trans-Game Information. This pattern in turn is defined as information that is passed from one game session to another game session. Sonic Adventure uses this pattern too. Chao go through several stages in their lives, from egg, child and adult, to death. The stages last from a few minutes (eggs), up to twenty hours (adult). If the Chao has enjoyed life, it will enter a pink cocoon and reincarnate. An egg will then be left so that Chao can enjoy life another time. In most cases Coupled Games are Asynchronous Games and "actions that take place in one game become Trans-game Information in the other" [14, p. 16]. 
With the pattern Coupled Games we investigate one mechanism of pervasive mobile learning games. In the context of our research the coupling comprises two components: short messaging services (SMS) notifications that we designed as a quiz and a PC-based browser game.

In order to assess the educational effects of the pattern Coupled Games for learners at-risk, this paper firstly provides an overview of related work on the use of SMS for education. Subsequently it outlines the educational intervention and technical infrastructure of the game. The paper then describes the methodology of the study and depicts how the characteristics of the target group have informed the game design and the methodological approach of the study. It concludes by presenting results of the study and discussing possible implications for future design decisions.

\section{RELATED WORK}

Before outlining the educational intervention, we present a representative selection of studies on the use of SMS notifications for educational purposes, followed by a discussion of their shortcomings and restrictions.

Text messaging has become the dominant mode of electronic communication amongst young adults and plays a central role in maintaining their social networks [2][22][23]. Building on this evidence, practitioners and academics are looking at the design and impact of SMS for teaching and learning [24][25][26][27]. Even though using SMS technology is a comparatively old concept, research into this field states that students' familiarity with this type of conversation [28], the minimal disruption it causes [29], the potential of for SMS for interactivity or the lowthreshold access it provides with regard to learning and technology [23][30] make it favourable for use in an educational context.

The study by Santos [27] showed that using SMS in the classroom encourages students' further thinking and exploration of course topics outside class time and Carvus [31] reports that using SMS effectively supports students' learning of new technical English language words. Attewell 
and Savill-Smith [32] argue that SMS provide low-threshold learning opportunities and, instead of inhibiting the learning of spelling and grammar as frequently suggested, contribute to improving young people's literacy (p. 5). Harley [2] stresses that text messages facilitate the development of productive relationships for those who would otherwise be socially isolated. A study on the impact of SMS on students' self-regulated learning strategies argues along these lines. It suggests using the principles of persuasive technology for sending SMS messages especially for the high risk students [33]. The study shows that students who received persuasive SMS intervention performed better than students who did not receive any SMS intervention. Additionally, the study demonstrates the positive impact of persuasive SMS on students' learning and suggests that the intervention can improve students' self-regulated learning effort. Crabtree et al., [34], in their report on the mobile game Day Of The Figurines, have evaluated the potential of a game that exploits SMS as a primary means of interaction. Their findings indicate that the success of the game relies on the "orchestration of messaging by behind the scenes staff" (p. 42). This for example includes "categorising messages so that appropriate next actions can be taken, which relies on interpretive work to make sense of messages" (p.42) or "crafting responses to engage players in the game" (p.43).

When using SMS in class, concerns with regard to costs for receiving and sending out SMS, learner focus and attention or intrusion into personal time [25] have to be well considered. However, they should not hinder the use of SMS in the classroom. "A pedagogically supported use of SMS within classrooms may allow for low-cost implementation of real-time, text-based interactions and put an end to the familiar refrain of "turn UR mobiles off" " [23].

Despite the use of SMS in class being reported as effective, little is known about what makes their use successful in an educational role. The paper by Yengin et al., [35] provides a detailed analysis of the technology used for SMS and gives examples of different research studies of successful implementations in education, but gives no explanation for the stated success by deducing guidelines, for example. However, the paper by Wang and Shen [36] does propose 
guidelines. Based on a review of tools used to design mobile media, e.g. the use of audio, captions or icons, Wang and Shen have set up message design principles for mLearning that consider learning theories and instructional design principles.

Based on this evidence, our research explores how SMS employed to realize the pattern Coupled Games may support learners at-risk. Our scenario uses SMS interventions in the form of a mobile learning quiz. The quiz is coupled with a PC-based learning game to evaluate how the pattern Coupled Games impacts students' motivation and learning outcomes. A similar approach has been adopted by Attewell [28]. Her study employed SMS as an entertaining addition to classroom lessons. Study results emphasize the relevance of mobile learning for atrisk learners, attracting young people to learning and supporting their learning and development. Mobile learning takes away some of the formality from the learning experience and engages reluctant learners. Beyond that, the use of mobile devices may counteract resistance to the use of ICT thus bridging the gap between mobile phone literacy and ICT literacy.

In the following we describe how we realized mobile learning in the context of an educational game that aims at improving ICT literacy for learners at-risk and outline the technical infrastructure.

\section{THE COUPLED GAME INTERVENTION}

\section{Instructional Approach}

The underlying pattern for the study is the pattern Coupled Games. We employed this pattern by coupling the browser-based multiplayer game BauBoss [37] and a mobile game extension. The multiplayer PC-based game BauBoss was introduced to foster the acquisition of skills and abilities of at-risk learners in using commonly used application software, i.e. Office [37]. It is based on the assumption that when games appeal to students, playing them will enhance their intrinsic motivation to learn and will improve learning [38]. Czauderna and Erlenbusch [39] in their study assessed and partially corrobrated this. 
[Fig. 1. Screenshot BauBoss]

The main intention of BauBoss is to bring at-risk learners "in touch" with IT-content. Therefore, applying IT knowledge is a vital way to score [37]. The game frequently offers questions from the European Computer Driving Licence (ECDL). The ECDL is a standardized test that reflects and certifies up-to-date skills and knowledge in computer use and common software applications. The questions are introduced by way of a ringing telephone the player can choose to answer or reject. Questions answered correctly have an in-game advantage, i.e. they increase the IT-Checker value (an expertise score) and a high IT-Checker value shortens the time to finish buildings. The quicker a building is finished, the quicker the player can generate money from letting it. This again influences the money index and respectively the score increases. To integrate the question more seamlessly, the player is asked to help a colleague (site foreman) who needs to send a construction plan for instance and requires help with regard to the most appropriate data format.

This mechanism was kept for the SMS-based game extension of the learning game. The mobile game extension was defined as a set of SMS notifications by way of multiple- and single-choice questions (SMS quiz). They were introduced as a request for help. The questions had to be answered quickly because only the first two participants sending correct answers received the bonus, which subsequently added to the IT checker value [37] of the coupled browser game BauBoss. In addition, we sent SMS messages that provided hints referring to IT-related subjects as well as hints containing personalized information on score notification of friends for example: "The cities of your friends have become prosperous. By enlarging your IT knowledge, you can quickly catch up." The messages were individually tailored to participants.

For the formulation of the SMS notifications we took into consideration the target group's literacy skills, e.g. we paid heed that the text be as short and clear as possible. Also, the messages were aligned to the target group's restricted attention span, i.e. multiple- choice 
questions with a choice of only four answers, and a maximum of approximately 50 words per message.

\section{[Table 1. Text messages sent to the experimental group]}

We designed SMS-based content that could be used on different devices and that was based on the type and the activities participants' devices could support [36]. In order to be able to do so we asked teachers to interview participants in advance with regard to the devices at hand (smartphones/mobiles/iPhones). The responses were received anonymously. We used 'captioned content' [36], which can significantly improve reading comprehension, word recognition or decoding skills and provides "the flexibility that is essential for mobile messages to be received in a variety of changing contexts" [36, p. 572]. Mainly, this was important because we sent out the SMS messages in the afternoon and participants received these messages on their private mobile phones.

We sent three messages per week outside class time, i.e. before the sessions, for lunch break, or in the afternoon: a) hints referring to IT-related subjects, b) hints containing information such as notification of friends' scores, and c) multiple- and single-choice questions (quiz) relating to the BauBoss game. The hints referring to IT-related subjects were sent once a week (usually Fridays). With the knowledge notifications we meant to support general interest in IT and to refresh content already learned.

The quiz questions were sent out two to three days later (usually Mondays). We provided instant feedback on the questions. The correct answer was provided in the case of both correct and incorrect replies. With this, further chunks of information were sent to the participants.

In the early morning before the browser game phase (usually Wednesdays), we sent hints containing information on friends' scores. With this notification we aimed at supporting interest in the BauBoss game. 


\section{Technical Infrastructure}

From a technical point of view, the starting base and corresponding requirements for the experiment were very diverse. Ten out of 18 learners owned smartphones. The ten smartphones were equipped with four different operating systems (5 Symbian, 3 Android, 1 Bada, 1 iOS). Eight participants owned a conventional mobile phone. Purchasing smartphones for the experiment was not mandated. Thus the prototype, initially developed to evaluate the impact of coupled games in affective and cognitive learning outcomes [40], could not be used. The devices would have had to be loaned by the instructor who would have been liable for theft and loss of class time.

This led to the decision to settle on conventional mobile devices as a "common denominator" and on the use of text messaging via SMS, a service which is available on all mobile phones. This way, all learners could participate using their own devices for the game. On the other hand, participants had to pay network charges for sending the messages, a potential drawback [41]. We addressed this problem by offering a cash rebate for the messages sent.

To send and receive text messages, we used an SMS voting system (http://www.openit.de/smseinsatz.html). Technically, an integration of the mobile quiz game into the browser-game BauBoss was possible and thus considered but due to interfering project tasks postponed. However, the decision to use an SMS voting system had littlte bearing on the game design. The intended coupling of mobile quiz game and browser-game via the IT-checker value was still possible.

Through a number provided by the system we sent out messages and participants replied to the designated phone number. This way we were able to receive participants' answers in real time (live voting) and, at the same time, to collect the responses electronically for efficient data processing. The system sorted all incoming SMS according to date, time, telephone number, and text (content). In addition, the system made it possible to group participants according to certain 
parameters such as message content, class, etc., which enabled us to customize text messages according to different categories of learners and to organize messages beforehand.

\section{METHOD}

Mobile learning games provide low-threshold learning opportunities that enable the development and improvement of confidence, autonomy, and engagement [8][9]. Also, the use of SMS for learning has been found to enable low-threshold learning opportunities that support learning [32][33]. However, little is known about how mobile learning by way of games and SMS actually influence learning. Our research aims at contributing to research in the field. By combining mobile game-based learning and SMS messages its main objective is to understanding how the pattern Coupled Games influences both information access and motivation for at-risk learners. We thus formulated the following two hypotheses.

H1: Participants receiving SMS interventions will show higher motivation to deal with IT content in general and software applications in particular than those playing the PC-based verson of the game BauBoss.

H2: Participants receiving SMS interventions will perform better (higher knowledge gain) than the pupils playing the PC-based version of the game BauBoss (no mobile intervention).

\section{Participants}

We carried out the experiment in spring 2012 (January-March). A total of 19 learners from state-funded professional qualification programmes offered by the Education Centres for the Building Industry (Bildungszentren des Baugewerbes e.V.) aged from 16 to 21 years participated in the study for seven weeks. The target group consisted of male participants only. From various points of view, this is a very challenging task. For one, the target group cannot easily be described as homogeneous. The 19 participants had very different (and partly very difficult) learning histories as well as diverse social backgrounds and cognitive capacities. Only a few of them have a school-leaving certificate. In general, the target group is difficult to 
motivate. Their low self-esteem, low frustration tolerance and poor stamina leads to high dropout rates. Most participants frequently use mobile devices, but mainly for communication (texting messages, calling friends).

For the intervention, participants were randomly assigned to one of two groups, experimental group $(n=10)$ and control group $(n=9)$. During the sessions, both groups played the multiplayer browser game BauBoss. After the session, both groups were asked to carry on playing at home.

The experimental group additionally dealt with the mobile learning game (coupled game which comprised browser game and SMS interventions). The control group dealt with the PC-based version of the game only.

\section{Measures}

Data were collected through questionnaires and interviews. To capture information on both motivation and knowledge gain, we mixed a) qualitative data such as open-ended and bounded questions with b) quantitative data coming from a standardised test and event log files generated automatically by the game.

Motivation to learn. This measure contained a post-game qualitative questionnaire with 15 questions loosely based on a combination of already existing questionnaires to measure player engagement [42][43] and an interview. The 15 items from the questionnaire were arranged for scoring on a five-point Likert scale, ranging from 'agree strongly', through 'agree', 'not certain' and 'disagree', to 'disagree strongly'. For average and standard deviation calculations we assigned value $\mathrm{SA}$ as five points, $\mathrm{A}$ as four points, $\mathrm{NC}$ as three points, $\mathrm{D}$ as two points and $\mathrm{SD}$ as one point. We evaluated participants' response to the game and the corresponding SMS interventions. The questionnaire included bounded questions designed to obtain feedback on engagement, attitude towards IT learning, game play, group and game experience.

Knowledge Gain. Due to the rather heterogeneous group of learners we used a pre- and a posttest to measure the learning effects of the intervention. Both tests comprised the same set of 80 
IT test items. In order to ensure a mapping of results we used key numbers for the participants. The test was adapted from the ECDL. The ECDL tests were administered under the supervision of teachers and two investigators.

In addition, we added data from learner tracking. These data comprise log-in times, handling of IT questions, use of networks and chat, etc. They complement the qualitative and quantitative results and document the real user data. Both the data from learner tracking and from the ECDL test could be traced back to individual participants due to a coherent use of key numbers.

\section{FINDINGS}

In the following we present the results from our study. The experimental setting comprised five, moderated gaming sessions. Each session lasted between 60 and 70 minutes.

\section{Motivation and knowledge gain}

For motivational aspects, we analyzed participants responses to a questionnaire. From a total of 19 participants, five did not manage to complete the questionnare. As a result, 6 students remained in the control group while 8 students remained in the experiment group.

Hypothesis 1: Participants receiving SMS interventions will show greater motivation to deal with IT content in general and software applications in particular than those playing the PCbased verson of the game BauBoss.

Table 2 compares the control and experiment groups' motivation to deal with IT content in general and software applications.

[Table 2. Comparing the control and experiment groups' motivation to deal with IT content in general and software applications]

The mean opinion scores and standard deviations of students' survey responses are given in table 2 and 3. At a glance, the results suggest that students from both the experimental and the 
control group shared the same viewpoint upon this issue. However, with regard to question items $2,4,5$ and 10 there were differences. These items took the use of computers for work into consideration. As for question item 2 the mean value of the responses for the experimental group was $3.625(\mathrm{SD}=1.251)$, control group $2.333(\mathrm{SD}=1.247)$ and for question item 4 the mean value of the responses for the experimental group was $3.625(\mathrm{SD}=0.857)$, control group 2.833 $(\mathrm{SD}=0.687)$. Further more, question item 5 reveals that the experimental group tends towards liking the topic. The experimental group $(\mathrm{M}=1.75, \mathrm{SD}=0.661)$ did not find the topic as boring as the control group $(\mathrm{M}=2.5, \mathrm{SD}=1.5)$.

Table 3 shows that in the dimension of looking at IT content in the IT-Café, a difference of average score for experimental group and control group is recognizable (experimental group $\mathrm{M}=3.5, \quad \mathrm{SD}=0.707$; experimental group $\mathrm{M}=2.167, \quad \mathrm{SD}=0.898$ ). Participants from the experimental group rather used the IT-Café to look up content and thus to better play the game.

In the dimension of collaboration (question item 12), the average score for both groups is comparable with the score of $\mathrm{M}=1.75$ (experimental group) and $\mathrm{M}=1.667$ (control group) and the standard deviation of 0.433 and 0.623 respectively, which indicates that participants shared the same view point upon this issue, i.e. they answered the questions on their own.

[Table 3. Comparing the control and experiment groups' motivation to deal with

\section{IT content in the game]}

For learning effects, we analyzed participants pre- and post-test results.

Hypothesis 2: Participants receiving SMS interventions will perform better (higher knowledge gain) than the pupils playing the PC-based version of the game BauBoss (no mobile intervention).

Table 4 is based on six responses from the experimental group and six responses from the control group for both the ECDL pre- and post-test. One student who only participated in the 
pre-test was beforehand omitted from the data. The pre-test was conducted before the first game session in January 2012 and the post-test after the last game session in March 2012.

\section{[Table 4. Results from the IT testing]}

Results from the IT testing indicate that participants from the experimental group attained higher scores on the pre-test (experimental group $\mathrm{M}=63.83, \mathrm{SD}=10.221$; control group $\mathrm{M}=$ 62.83, $\mathrm{SD}=11.495)$. However, in the beginning both groups already had different previous knowledge. This makes an evaluation of the impact of coupled games on knowledge gain difficult. However, the results given in table 4 show that participants who played the mobile learning game attained higher scores on the knowledge post-test with smaller standard deviations (experimental group $\mathrm{M}=69.33, \mathrm{SD}=8.38$; control group $\mathrm{M}=65.5, \mathrm{SD}=13.238$ ). This effect also applies to the variation of standard deviation for the experimental groups' pre- and post-test (pre $\mathrm{SD}=10.221$, post $\mathrm{SD}=8.38$ ). Thus, from the IT testing a clear effect of the intervention (playing the mobile learning game) showed for the experimental group.

Participants from both the experimental and the control group answered IT questions within the browser game BauBoss while playing.

[Table 5. Questions answered within the game BauBoss]

\section{Student feedback to the SMS interventions}

Participants from the experimental group who played the mobile game demonstrated a rather reluctant attitude towards the use of text messages. Our study revealed that initially participants were very reluctant. To them, BauBoss belonged to schooling activities and thus had no relevance to their everyday life. After a while however, they started to accept the intervention. One participant explained, 
P1: "No, in the beginning I thought, this is pretty annoying. But after a while, got the SMS, talked with friends. Because most of the time we're all out together. And then, 'Ah, I got an SMS from BauBoss.' 'Yes, then I'll get one too, for sure.' Then we answered the question together.'

P2: “Not bad. When you're out, as a reminder. You're still playing BauBoss, getting an SMS, you can simply and instantly play the game a little, it was actually not bad."

Most of them valued the collaborative and social dynamics of the game:

P3: "When the SMS came, yes, some said, 'BauBoss again', and I, and others then (said) 'Oh BauBoss!'. And then we talked, yes once we even sat together with some people and an SMS came, from BauBoss again, and (we) then really fiddled and kept thinking about it, what is it again? And then I said 'Well boys, you have to boost the IT-Checker.' And then I answered the question and that was it."

Conversely, three participants expressed dislike for the quiz messages. When questioned why, they mentionned money. They expected costs despite the fact that it was made clear beforehand that any costs would be refunded. One participant did not state a clear reason (e.g. money, lack of knowledge) for not responding to the SMS questions.

\section{DISCUSSION}

Results show a tendency with regard to affective and cognitive learning outcomes. Participants from the experimental group showed a more positive attitude towards the subject. Also, learners who played the mobile learning game had a higher knowledge gain. It can be argued that evidence for possible cognitive learning outcome is based on the higher number of questions and information, i.e. the experimental group had more opportunities to learn. With regard to the total number of obligatory questions this might be correct. But besides this, every learner had access to all questions at any time. They were accessible via the IT Café. This way, every learner had the same opportunities to learn. In our opinion, the important aspect is the fact that participants accepted the input and dealt with the corresponding IT content, which eventually led to a higher knowledge gain. This is a valuable aspect with regard to the target group. In 
addition, as backed up by the learners' statements, the educational intervention triggered social dynamics and collaboration amongst learners, which is a valuable aspect with regard to the target group too.

When interpreting the results we have to consider whether the results can be attributed at least partially to short-term effects of novelty. We assume that our educational study does not suffer badly from this argument because we compared a variation within a learning environment that was new to both groups alike (the brower-game BauBoss). Also, the technology we used (SMS messages) was not a thrilling novelty. Learners are frequently dealing with it. Still, teaching changed and learning implied technology that is unusual within traditional school settings and culture [44]. Long-term studies are thus necessary to assess whether effects change during repeated use and over time.

Due to the high dropout rate, a regular problem when working with the target group, our test audience is rather small, which makes generalization difficult. Also, only males play-tested the game. In order to corroborate effects that show in our study, large scale testing is necessary that additionally takes gender into consideration.

The study emphazises the relevance of mobile SMS for young male at-risk. We expect that the positive effects do not decrease after one use but assume that participants would still be interested in the apporach and likely have more information gain. The use of SMS seemingly caused a change for the target group and helped them learning, which is a vital result because motivating at at-risk learners and supporting their learning is both a challenging and vital task. Mobile game-based learning approaches are regarded as powerful tools to back efforts in that direction. They are interactive thus promoting an active learning environment and facilitate the building of learning communities [23]. Our study demonstrates how mobile games can be employed for educational settings by example of coupled games. This pattern allows us to use the potentials of mobile phones in a very targeted manner, both as an extension to an existing learning game and as a channel for information. Despite the relatively small sample size we may 
draw conclusions from our experiment with regard to the use of SMS messages for the target group.

With regard to the patterns applied, the experiment was designed as coupled game. Other patterns were not explicitly part of the initial mobile learning game design. However, we are aware that related research has argued that game design patterns should not exist alone and that choosing one game design pattern almost automatically requires the presence of other game design patterns [45]. As for our experimental setting, the aspect of collaboration for example was a result of the pattern in use. Students stated that they collaborated in order to answer the quiz questions correctly (see participants' statement P3). However, we did not make explicit use of this pattern when designing the game play. With the given technical set-up, there was no actual collaboration possible and implemented on the basic level of SMS quiz. The system we chose enabled sending SMS from the system to the user and reverse. In order to diminish possible drawbacks due to network charges for users, we offered a cash rebate. Further research on notifications systems, such as the approach by Chiu et al., [46] however, has considered amplified systems that interact with users, providing real-time notifications with multimedia message formats for example. Such an set-up will be considered for further research.

Despite the target group is very attracted to communicating via SMS, our assumptions for the game play have not comprehensively proved right. Feedback from the interviews shows that simply sending messages is not necessarily attractive to them and does not thrill them to make use of the learning offer provided. One participant stated that he was annoyed by the SMS questions as he had received the messages at times when he did not expect them (outside the sessions in the afternoon, esp. during lunch time). The time when sending the messages and moreover the actual graphical design of the mobile game surely affects the acceptance and the effects of its use. The target groups' low frustration tolerance reflects in their low willingness to tolerate prototypical grafical interfaces for example. We assume that a state-of-the art mobile game with an appealing graphic interface is more likely to attract their attention and thus their 
willingness to play the game. This conclusion is fortified by current research [40]. Though the growing pedagogic and technological sophistication of mobile learning pilots is evident, increased and sustained deployment of mobile learning will depend on the quality of analysis and evaluation of these pilots and trials [47]. Thus, future research needs to address the importance of the GUI on motivational and learning aspects as well as different game scenarios. Still, the mobile learning intervention showed positive effects.

\section{CONCLUSION AND FUTURE WORK}

This paper's contribution to research in the field is based on three pillars. First, we provided an overview of the use of SMS for education. We have reflected on a concise and effective use of the pattern Coupled Games and mobile game-based learning in education. Our intention was to enhance insight into the motivational and learning effects of such environments from a pattern design perspective by focusing on the coupled games and the use of text messaging. Second, we have exemplary described a low-threshold mobile game scenario that couples SMS messages with an existing browser game. With the coupling, this study presents a multifaceted learning environment that is able to cope with current problems in learner motivation. Third, we have presented results from a study that assessed the impact of the pattern Coupled Games on at-risk learners with regard to motivation and knowledge gain. From the study it showed that coupled games have positive effects on students' learning and suggests that the intervention is able to improve students' interest in dealing with the topic.

However, further research is needed to comprehensively evaluate the potential and effect of this pattern, in isolation and in combination with other patterns. An upcoming experiment will further evaluate the impact of coupled games on motivational aspects. The experimental design will include a mobile learning game with coupled SMS notifications for Basic Life Support (BLS). We assume a positive impact on a person's belief in his or her ability to succeed in a particular situation (self-efficacy) as described by Bandura [48] and a possible impact on a person's willingness to help. Results from this study will be published in due course. 


\section{References}

1. E. Klopfer, J. Sheldon, J. Perry, and V. H.-H. Chen, Ubiquitous games for learning (UbiqGames): Weatherlings, a worked example, Journal of Computer Assisted Learning (2011), doi: 10.1111/j.1365-2729.2011.00456.x

2. D. Harley, S. Winn, S. Pemberton, and P. Wilcox, Using Texting to Support Students' Transition to University, Innovations in Education and Teaching International, 44/3 (2007) $229-241$.

3. M. Dunleavy, C. Dede, and R. Mitchell, Affordances and limitations of immersive participatory augmented reality simulations for teaching and learning, Journal of Science Education and Technology, 18/1 (2009) 7-22.

4. T. H. Laine, M. Vinni, C. I. Sedano, M. and Joy, On designing a pervasive mobile learning platform. ALT-J, Research in Learning Technology, 18/1 (2010) 3-17.

5. T. M. Conolly, M. Stansfield, \& T. Hainey, An alternate reality game for language learning: ARGuing for multilingual motivation. Computers \& Education, 57/1 (2011) 1389-1415.

6. E. Klopfer, Augmented Learning. Research and Design of Mobile Educational Games. The MIT Press (Cambridge, Mass., 2008).

7. M. Specht, Learning in a Technology Enhanced World. Context in Ubiquitous Learning Support, Inaugural Address spoken at the Open University of the Netherlands (2009).

8. J. Traxler, Distance education and mobile learning: Catching up, taking stock, Distance Education, 31/2 (2010) 129-138.

9. R. Douch, J. Attewell, and D. Dawson, Games technologies for learning. More than just toys. LSN (London, UK 2010) Retrieved 12.04.2011 from: https://crm.lsnlearning.org.uk/user/order.aspx? code $=090258$. 
10. M. Mascherini, Young people and NEETs in Europe: First findings, EUROFOUND (Dublin, 2011). Retrieved 10.10.2012 from: http://www.eurofound.europa.eu/pubdocs/2011/72/en/1/EF1172EN.pdf

11. C. Pierce, 'Importance of classroom climate for at-risk learners', Journal Of Educational Research, 88/1 (1994) 37.

12. R. Simmons, and R. Thompson, Education and training for young people at risk of becoming NEET: findings from an ethnographic study of work-based learning programmes, Educational Studies, 37/4 (2011) 447-450

13. J. M. Richman, L. B. Rosenfeld, G. L. Bowen, Social Support for Adolescents at Risk of School Failure, Social Work, Vol. $43 / 4$ (1998) 309 -323

14. O. Davidsson, J. Peitz, and S. Björk, Game design patterns for mobile games, Project report to Nokia Research Center, Finland, (2004). Retrieved 14.04.2010 from: http://procyon. lunarpages.com/ gamed3/docs/Game_Design_Patterns_for_Mobile_Games.pdf

15. J. Peitz, Coupled Games. Enhancement of Video Games using Mobile Functionality. Master thesis in Computer Science at Chalmers University of Technology (2004). Retrieved, 22.09.2011 from: http://www.tii.se/play/projects/gamepatterns/publications.html

16. B. Schmitz, R. Klemke, and M. Specht, Effects of mobile gaming patterns on learning outcomes: A literature review, International Journal of Technology Enhanced Learning, 4/56, 345-358.

17. S. Björk, S. Lundgreen, and J. Holopainen, Game Design Patterns. In: Copier, M. Raessens (Ed.): Level up - proceedings of digital games research conference (Utrecht, The Netherlands 2003).

18. J. Cook, Mobile Phones as Mediating Tools within Augmented Contexts for Development, International Journal of Mobile and Blended Learning, 2/3 (2010) 1-12. 
19. D. Maciuszek, and A. Martens, Patterns for the Design of Educational Games. In: Edvardsen, F. and Kulle, H. (Eds.), Educational Games: Design, Learning, and Applications (Novapublishers 2010) 263_280.

20. S. Kelle, R. Klemke, and M. Specht, Design patterns for learning games, International Journal of Technology Enhanced Learning, 3/6 (2011) 555-569.

21. K. Kiili, and H. Ketamo, Exploring the Learning Mechanism in Educational Games, Journal of Computing and Information Technology - CIT, 15/4 (2007) 319-324.

22. S. Porath, Text Messaging and Teenagers: A Review of the Literature, Journal Of The Research Center For Educational Technology, 7/2 (2011) 86-99.

23. C. Markett, I. A Sánchez, S. Weber, and B. Tangney, Using Short Message Service to Encourage Interactivity in the Classroom. Computer \& Education, 46/3 (2006) 280-293.B. Schmitz, R. Klemke, and M. Specht, Effects of mobile gaming patterns on learning outcomes: A literature review, Accepted for: International Journal of Technology Enhanced Learning (2011).

24. A. A. Ziden, and F. A. Rahman, The Use of SMS Quiz System as an Alternative in Teaching and Learning. 11th World Conference on Mobile and Contextual Learning (mLearn 2012), 16-18 October 2012, Helsinki, Finland, 266-275.

25. P. Brett, Students' experiences and engagement with SMS for learning in higher education. Innovations in Education \& Teaching International, 48/2 (2011), 137-147.

26. T. Lim, M. Fadzil, and Norziati Mansor, Mobile Learning via SMS at Open University Malaysia: Equitable, Effective, and Sustainable. Open University Malaysia, Malaysia (2011).

27. I. M. Santos, FINDING OPPORTUNITIES TO USE SMS IN THE CLASSROOM, in: Proc. IADIS Int' Conference Mobile Learning 2010, (Porto, Portugal, 2010) 45-52. 
28. J. Attewell, Mobile Technologies and Learning: a technology update and m-learning project summary. Learning and Skills Development Agency (London, 2005).

29. L. Horstmanshof, Using SMS as a way of providing connection and community for first year students, in: Proc. ASCILITE 2004, (University of Western Australia, Perth 2004). Retrieved August 29, 2008 from http://www.ascilite.org.au/conferences/perth04/procs/pdf/horstmanshof.pdf

30. S. H. Kim, C. Mims, and K.P. Holmes, An introduction to current trends and benefits of mobile wireless technology use in higher education. AACE Journal, 14/1 (2006) 77-100.

31. N. Carvus, and D. Ibrahim, M-Learning: An Experiment in Using SMS to Support Learning New Language Words, British Journal of Educational Technology, 40/1 (2009) 78-91.

32. J. Attewell and C. Savill-Smith, Mobile learning and social inclusion: focusing on learners and learning, in: Jill Attewell, Carol Savill-Smith, eds, Learning with mobile devices. Research and Development. (London, Learning and Skills Development Agency, 2004).

33. T.-T. Goh, B.-C. Seet, and N.-S. Chen, The impact of persuasive SMS on students' selfregulated learning, British Journal of Educational Technology (2011), doi:10.1111/j.14678535.2011.01236.x.

34. A. Crabtree, S. Benford, M. Capra, M., Flintham, A. Drozd, N. Tandavanitj, M. Adams, and J. R. Farr, The Cooperative Work of Gaming: Orchestrating a Mobile SMS Game. Computer Supported Cooperative Work (CSCW), 16/1-2 (2007) 167-198.

35. I. Yengin, A. Karahoca, D. Karahoca, and H. Uzunboylu, Is SMS Still Alive For Education: Analysis Of Educational Potentials Of SMS technology?, in: Proc' Computer Science 3 (2011) 1439-1445.

36. M. Wang, and R. Shen, Message design for mobile learning: Learning theories, human cognition and design principles, British Journal of Educational Technology (2011), doi:10.1111/j.1467-8535.2011.01214.x. 
37. B. Schmitz, and A. Czauderna, Designing a Browser Game to Engage Learners Difficult to Reach in IT Learning, in: Proc. GameDays (Darmstadt, Germany 2011) 41-53.

38. D. Charsky, W. Ressler, "Games are made for fun": Lessons on the effects of concept maps in the classroom use of computer games, Computers \& Education (2010), doi: 10.1016/j.compedu.2010.10.001.

39. A. Czauderna, E. Erlenbusch, Evaluation des Computerlernspiels 'BauBoss'. In: Kaminski, W. and Lorber, M. (Eds.), Gamebased Learning (kopaed, München 2012).

40. B. Schmitz, M. Hoffmann, R. Klamma, R. Klemke, and M. Specht, Developing a Mobile Game Environment to Support Disadvantaged Learners. Proc. ICALT 2012, IEEE International Conference on Advanced Learning Technologies (IEEE Computer Society CPS 2012) 223-227.

41. S. L. Cheung, Using Mobile Phone Messaging as a Response Medium in Classroom Experiments, Journal of Economic Education, (2004). Available at Social science research network (SSRN): Retreived 12.03.2011 from: http://ssrn.com/abstract=906681

42. L. J. Francis, Measuring attitude toward computers among undergraduate college students: The affective domain, Computers \& Education, 20/3 (1993) 251-255.

43. T. Malone, What makes things fun to learn? A study of intrinsically motivating computer games, Cognitive and Instructional Sciences Series CIS-7 (SSL-80-11), (Palo Alto, CA: XEROX Palo Alto Research Center, 1980).

44. S. Price, Ubiquitous computing: digital augmentation and learning, in Pachler, N. (Ed.) M-learning: towards a research agenda. WLE Centre occasional papers in work-based learning, (Institute of Education, London 2007) 32-53.

45. S. Kelle, Game Design Patterns for Learning, Proefschrift. (Shaker Verlag, Aachen, 2012). 
46. C.-H. Chiu, R.-S. Wu, C.-I. Tut, H.-T. Lin, S.-M. Yuan, Next Generation Notification System: Integrating Instant Messengers and Web Service, in: Proc' ICCIT (2007), doi : 10.1109/ICCIT.2007.304.

47. J. Traxler, and P. Dearden, The Potential for Using SMS to Support Learning and Organization in Sub-Saharan Africa. Proc. of Development Studies Association Conference, (Milton Keynes, UK 2005).

48. A. Bandura, Self-efficacy, in: V. S. Ramachaudran, ed., Encyclopedia of human behavior, (Academic Press, New York 1994) 71-81. 